“Transfer” XV: 1-2 (2020), pp. 451-473. ISSN: 1886-554

\title{
DE GÉNERO Y TRADUCCIONES. \\ TRES PERSONALIDADES EN LA CULTURA DE SANTA FE: MARTA SAMATAN, LINA BECK BERNARD, PHILIPPE GREFFET
}

\author{
Silvia Zenarruza Clément (ORCID 0000-0003-3106-1239) \\ Universidad Nacional del Litoral
}

Nos convocan tres nombres de personalidades, las tres de orígenes diferentes que no fueron forzosamente coetáneas pero cuyo común denominador fue su ascendencia francesa o francófona que dejaron su impronta en la vida cultural y literaria de la ciudad de Santa Fe. Dos de ellas mujeres, por su trayectoria en defensa de derechos inalienables y también como escritoras; y Philippe Greffet, por su singularidad y sobre todo por el amor que evidenció hacia esta ciudad en sus escritos auto traducidos.

La primera de ellas, Marta Samatan, nacida en Chile, en 1901 de madre chilena criolla y de padre francés quien se instaló en la ciudad de Santa Fe afectado a la compañía de Ferrocarriles franceses cuando Marta tenía cuatro años. Joven y mujer de avanzada para su época, Marta será maestra normal y dejará su impronta en la docencia y en la organización del magisterio de la Provincia. Sus luchas y sus desilusiones quedarán plasmadas en Campana y horario:

Trabajar para el niño, solamente para el niño, no para los directores e inspectores. Esa fue mi consigna y empecé a cumplirla con el corazón liviano ante una danza loca de esperanzas. (Samatan, en Travadelo 2001: 15)

Comprovinciana y amiga de Gabriela Mistral, intercambiando y compartiendo ideas con Victoria Ocampo y Alfonsina Storni -que se alojaba y organizaba tertulias en casa de Marta cuando venía a Santa $\mathrm{Fe}$ - su trayectoria en el medio santafesino tendrá un impacto indiscutible. En efecto, tempranamente adhiere a las 
“Transfer” XV: 1-2 (2020), pp. 451-473. ISSN: 1886-554

corrientes progresistas que trataban de imponer el voto femenino e integra agrupaciones que movilizaban a mujeres de diversas clases sociales en contra de modificaciones regresivas del Código Civil. Su pensamiento político y social se plasma en su actividad gremial, por una parte y en su vocación de escritora, por otra. Recordemos que, con la inmigración masiva en las primeras décadas del siglo XX, se propagaron en nuestro país las doctrinas sociales que defendían los derechos del proletariado y de las mujeres en las ciudades portuarias que crecían aceleradamente, y Santa Fe cambiaba su fisonomía y sus costumbres provincianas de ciudad colonial y tradicionalista justamente gracias a esa inmigración, en gran parte francesa y francófona venida con el Ferrocarril francés y la construcción del puerto. La actividad docente de Marta la llevará a las luchas gremiales en la defensa del legítimo derecho a un sueldo justo. Vivirá avatares de ceses y reincorporaciones por haber participado en la huelga docente de 1921. Un hito en estos combates es la creación de la Asociación del Magisterio de Santa Fe en junio de 1928 que la tendrá como su presidenta.

Convencida de que para tener éxito en la defensa de sus ideales debía estar mejor preparada, se inscribe en la Universidad para cursar estudios de derecho. Obtiene su título en 1927 siendo una de las primeras egresadas de la Universidad Nacional del Litoral, aunque no ejercerá jamás la profesión. En 1932 declaraba:

He olvidado que soy abogada y sólo he recordado mi título para consignarlo en mi ficha personal (...) Soy maestra, y en las filas del magisterio pienso seguir luchando por los ideales que deben ser estandarte de nuestro gremio. (Martínez Trucco, en Coudanes 2011: 8).

Integrará además el Frente o Comité Popular Antifascista santafesino, y en 1936 creará y presidirá la filial santafesina de la Unión Argentina de Mujeres, presidida a nivel nacional por Victoria Ocampo y luego por María Rosa Oliver. 
“Transfer” XV: 1-2 (2020), pp. 451-473. ISSN: 1886-554

En el año 1938 ingresa por concurso al cargo de traductora de francés e italiano en la Facultad de Ciencias Jurídicas y Sociales de la UNL. Allí despliega una amplia tarea ligada a la defensa de la Universidad reformista. En los años del gobierno peronista es cesanteada por su pensamiento político y su acción, y debe ganarse la vida como traductora de una editorial de Buenos Aires. En 1955 se reintegra a la Universidad -con actos públicos de desagravio promovidos por el Delegado Interventor Domingo Bonocuore. Con su regreso a la Universidad se le confía la organización del Departamento de Pedagogía Universitaria y será una colaboradora frecuente de la revista Universidad, donde publicará ensayos propios y reseñas bibliográficas sobre educación, poesía, obras de escritores argentinos y españoles, temas femeninos, teatro, entre otros. Las primeras publicaciones científicas de Jean-Claude Filloux aparecidas en castellano son traducidas por ella y por el Dr. Ovide Menin y editadas por la Universidad a partir de 1961. Ovide Menin (2001: 22) evoca el trabajo silencioso de Marta Samatan clasificando y cuidando la mejor biblioteca especializada en pedagogía universitaria de entonces, la primera del país, ahora desmembrada.

Desde aquella biblioteca salieron pequeñas publicaciones en forma de cuadernillos sobre temas específicos. En el ámbito de aquella biblioteca tradujimos, de Jean Claude Filloux, en 1962, tres trabajos breves sobre la Psicología de los pequeños grupos, tema en cuyo abordaje fuimos pioneros. (Menin 2001: 22)

Recuerdo otra anécdota: Gabriela Mistral le dijo una vez, en carta que ella atesoraba: "yo le vuelvo a encargar que trabaje su francés, Marta. Y para obligarla, le digo que yo trabajo mi inglés y repaso mi italiano". Vive dios que Marta lo trabajaba; soy testigo de ello. Porque en una de esas tórridas siestas santafesinas, mientras me señalaba el amplio significado de una sintaxis poco agraciada de mi traducción de Filloux, me aplicó la recomendación; "Trabaje su francés, Ovide, porque usted lo pronuncia como un campagnard. (Menin 2001: 23) 
“Transfer” XV: 1-2 (2020), pp. 451-473. ISSN: 1886-554

Después de transitar por diferentes cargos, como Interventora primero y luego Directora interina de la Biblioteca de la Facultad que había debido abandonar años atrás y como Directora interina de Extensión Universitaria desde 1959, se retira de la vida universitaria en 1966.

Su escritura revela su constante accionar civil por la reivindicación de los derechos femeninos, la necesidad de liberar a la mujer de la situación de incapacidad y sujeción en la que estaba retenida por antiguos prejuicios por lo que hoy podríamos estudiarla desde una perspectiva de género.

Con respecto a su único libro de poemas Cantos de la vida diaria (Buenos Aires 1930), Delia Travadelo nos dice que

Los motivos nos hacen asociar sus versos con los de Evaristo Carriego: tienen esa misma poesía triste, sentimental, en tono menor. Prevalece el tema de la mujer frustrada, malograda por un medio adverso, sin posibilidades de realización personal, esa constante de su prédica y de su quehacer literario y humano. (Travadello 2001: 46)

Motivos que se repetirán en sus dos novelas: Penumbra (1966) y Ocaso (publicada póstumamente en 1981). Marta sigue el consejo de su amiga Gabriela Mistral y aborda, con su ficción, la atmósfera asfixiante, monótona y gris del barrio y la vida rutinaria y sin expectativas de los personajes femeninos. Mujeres que son oprimidas en su seno familiar -maestras santafesinas de escuelas suburbanas-, que reproducirán más tarde las mismas pautas establecidas por una sociedad que niega todo viso de superación y realización para ellas.

En 1976 recibe el Premio a la labor Literaria de la Asociación Santafesina de Escritores por el conjunto de su obra, entidad de la que había sido presidente en dos períodos.

Fallece en Santa Fe el 27 de julio de 1981.

En marzo de 2008, en el marco de los actos por la semana internacional de la mujer, la Universidad Nacional del Litoral hará 
“Transfer” XV: 1-2 (2020), pp. 451-473. ISSN: 1886-554

efectivo su tributo imponiendo el nombre de Marta Samatan a su Archivo Histórico.

\section{Lina Beck Bernard}

De esta extraordinaria mujer, que transitó nuestra región en el siglo XIX, hemos hablado recientemente en el libro Trilogía narrativa y ensayos Lina Beck-Bernard (Crolla 2018) y en el prólogo de la traducción en mi carácter de traductora. Lina llegará a estas tierras junto con su esposo Charles Beck, director principal de la Sociedad Colonizadora Suiza Beck y Herzog, encargado de llevar a cabo un convenio de colonización en la región de Santa Fe. El viaje es relatado por Lina en el libro Le Rio Parana. Cinq années dans la Confédération argentine. Su radicación en la ciudad se extiende de 1858 a 1862, año en que la escritora vuelve a Lausana para dedicarse a las letras y al estudio de las cuestiones sociales. Pero este aparentemente corto período habrá servido a la lúcida observadora para evocar con detalles y colores precisos la vida en estas tierras en tres relatos que serán publicados bajo el título Fleur des Pampas: La estancia Santa Rosa, Telma, Frère Antonio.

Abordaremos dos aspectos referidos a Lina Beck-Bernard. Por un lado, su compromiso en defensa de la condición de la mujer -que hemos descubierto y traducido por primera vez al español- en los opúsculos Memoria sobre las prisiones de mujeres, Patronazgos preventivos para las mujeres y La pena de muerte. Por otro lado, haremos un breve comentario sobre nuestro trabajo de traducción, dando cuenta de las operaciones que hemos adoptado para hacer sus textos más accesibles al lector actual.

En Mémoire sur les prisons des femmes (Lausana 1869) así como en Causes préventives chez les femmes (Lausana 1872), después de haber visitado varias prisiones y observado la condición de detención de las mujeres, Lina analiza y opina sobre el tratamiento que les es dado. Se pregunta qué es lo que puede prevenir los delitos para responder de modo contundente: una 
“Transfer” XV: 1-2 (2020), pp. 451-473. ISSN: 1886-554

buena organización social. Consciente del denigrante lugar que el Código civil y la legislación han dado a las mujeres, acusa al Código penal de infringirle los peores castigos. Cita, por ejemplo, el Código penal de Zurich en su artículo 139 que castiga ocho veces más rigurosamente el adulterio en la mujer que en el hombre. Reclama la necesidad de una modernización de la legislación, heredera del Derecho Romano y del Derecho Germánico. Compara a las mujeres trabajadoras de la moderna industria con siervas o esclavas y afirma que las de clases acomodadas sufren el infortunio de ser consideradas como menores.

Lina llama la atención sobre las mujeres, ya sean que estén detenidas, o bien sobre su destino una vez liberadas. Critica agudamente las condiciones de su encarcelamiento y la falta de humanidad con la que son tratadas. Reivindica la posibi-lidad de recuperación de reclusas que son capaces de sentimientos de dedicación, generosidad y renunciamiento. Pero se pregunta qué es lo que la mayoría de esas mujeres pueden esperar cuando salen de prisión. Todas las puertas de la sociedad les están cerradas:

El desprecio, la desconfianza, la acogida más dura, muchas veces en el umbral de la casa paterna (feliz cuando ese umbral no se ha cerrado para ella), la falta de trabajo, el hambre, la miseria, la desesperación, y al final de todo eso, la recidiva... Ese es el modelo habitual. (Crolla 2018: 239)

Propone patronazgos intercantonales para los presos, hombres y mujeres, sostenidos con los fondos de la empresa de las Misiones de Basilea que por año recibe más de 800.000 francos:

¡Cuánto bien se haría en nuestra patria suiza con tales ingresos empleados en un patronazgo intercantonal para los presos, hombres y mujeres! En alojamientos para jóvenes obreras, en escuelas profesionales, en asilos para maestras y domésticos de edad avanzada y para los enfermos en las fundaciones agrícolas que evitarían a los niños abandonados, huérfanos o ilegítimos, el amargo recurso de ser ubicados por las comunas. (Crolla 2018: 268) 
“Transfer” XV: 1-2 (2020), pp. 451-473. ISSN: 1886-554

En cuanto a La pena de muerte, Lina repasa la historia de Europa constatando que a medida que la civilización avanza las leyes se vuelven menos bárbaras. Sin embargo la pena de muerte persiste en Suiza, en el cantón de Lausana, desde donde ella escribe. Lina critica la validez moral de un acto legal y recusa el efecto desmoralizador del espectáculo de los supliciados sobre la multitud ya que el espectáculo del patíbulo, lejos de desalentar el delito lo incrementa: "En Francia se ha probado muchas veces que los condenados a muerte eran hijos nietos o hermanos de gente ya ejecutada" (Crolla 2018: 227). Evoca condenas seguidas de ejecuciones que fueron reconocidas luego de haber sido dictadas sobre inocentes y propone elevar el nivel intelectual de un pueblo, pues así serán más raros los delitos castigados con la muerte.

Sostiene que la prisión perpetua es suficiente castigo y que en cuanto al deber de seguridad para la sociedad, una prisión bien organizada salvaguarda suficientemente al cuerpo social. El ensayo de Lina sobre la pena de muerte es de 1868. En 1874 el gobierno suizo votaba la abolición de la pena de muerte en sus cantones, reintroducida sin embargo en 1879, aunque con pocas ejecuciones. Durante la Segunda Guerra Mundial habrá diecisiete militares condenados a muerte por traición. Sólo en 1999 la abolición se inscribe en la nueva constitución y recién entonces la pena de muerte estará prohibida. ${ }^{1}$ Bien podríamos concluir que Lina Beck Bernard fue una pionera en abordar este tema.

\section{La traducción de los relatos}

La escritura de Lina es extremadamente clara y podríamos llamarla moderna. Raras han sido las dificultades que tuvimos en el

${ }^{1}$ En: <<https://helvetiahistorica.org/2018/03/18/peine-de-mort-suisse/>> (Última fecha de consulta 25/05/2019). 
“Transfer” XV: 1-2 (2020), pp. 451-473. ISSN: 1886-554

ejercicio de traducción de sus tres novelas y de sus ensayos. Sin embargo debimos sortear aquí y allá algunos escollos. Así, en Memoria sobre las prisiones se nos presentó el obstáculo de la palabra "miser" que Lina Beck escribe en itálica, para la que elegimos ubicar.

En diccionario en línea Reverso, hemos encontrado la siguiente definición: miser: Vi. Suisse vendre, acheter aux enchères. (Vender o comprar en una subasta).

No nos pareció apropiado según el contexto optar por "subastar" o "vender" por lo que elegimos "ubicar". Veámoslo:

Notre système suisse qui fait miser dans leurs communes les enfants orphelins abandonnés ou illégitimes, amène les plus fatales conséquences. Demandez à nos juges d'instruction, présidents de tribunaux, directeurs de prisons, ils vous diront combien souvent, ces malheureux enfants misés fournissent leur contingents aux bancs des accusés et aux cellules des prisons.

Nuestro sistema suizo que hace ubicar en sus comunas a los niños huérfanos abandonados o ilegítimos, acarrea las más fatales consecuencias. Pregunten a nuestros jueces de instrucción, presidentes de tribunales, directores de prisiones, les dirán cómo, generalmente, esos desdichados niños ubicados alimentan los contingentes de los banquillos de acusados y de las prisiones. (Crolla 2018: 253)

El opúsculo que tradujimos como Patronazgos preventivos, lleva como título original Causes préventives chez les femmes. Nuestra opción surgió a partir de la lectura del texto que preconiza una acción preventiva antes de que jóvenes en riesgo caigan en prisión.

En este texto hemos traducido literalmente "filles en carte" por "mujeres en carta", aludiendo a aquellas prostitutas que, no perteneciendo al mundo cerrado del prostíbulo, eran consideradas "insumisas" y sometidas a arrestos sorpresivos. La policía las identificaba con una cartilla ("carte") donde figuran sus datos y estado sanitario: 
“Transfer” XV: 1-2 (2020), pp. 451-473. ISSN: 1886-554

Mais les anciens caveaux de Saint Antoine ont été aménagés de manière à recevoir les femmes de mauvaise vie, appelées femmes en carte, et patentées comme telles par la police.

Pero los antiguos sótanos de Saint-Antoine han sido arreglados para recibir a mujeres de mala vida, llamadas mujeres en cartas, e inscriptas como tales por la policía. (Crolla 2018: 274)

Refiriéndose a una mujer que había sido detenida doce días después del parto y no había recibido ninguna atención médica, Lina Beck narra que:

Un dépôt de lait dans la main droite amena la carie des os, et après d'atroces souffrances et plusieurs opérations détermina l'amputation complète de la main.

No habiendo encontrado una explicación científica a la expresión "un dépôt de lait" lo tradujimos del siguiente modo:

Una caries de los huesos de la mano derecha provocó, después de atroces sufrimientos y varias operaciones la amputación de la mano. (Crolla 2018: 278).

\section{Tres novelas: La estancia Santa Rosa, Telma, Frère Antonio}

Estos tres relatos tienen como escenario las tierras de América, particularmente nuestra región de Santa Fe. En ellos, nada escapa al ojo de Lina: los habitantes y sus costumbres, las creencias, los trabajos, los sentimientos. En las primeras páginas de La Estancia Santa Rosa Lina ya previene al lector sobre el carácter de su relato: asegura que el estudio de las costumbres que narra no es una ficción ni tampoco una novela aunque a veces tenga apariencia de serlo: 
“Transfer” XV: 1-2 (2020), pp. 451-473. ISSN: 1886-554

Los personajes están tomados de la realidad: son recuerdos, hechos reales, que se han agrupado en un episodio característico de la vida hispano-americana. (Crolla 2018: 59).

Sin embargo, el relato no deja de tener tonos poéticos con acertadas comparaciones: "En la vida simple y monótona del desierto, los días pasan rápido, como la flecha de los indios". (Crolla 2018: 76).

En nuestro trabajo de traducción, hemos creído necesario adaptar el texto al lector y, por ende, aggiornarlo al público argentino que vería hoy como redundantes ciertas explicaciones destinadas, en principio, a un lector europeo de la época en que se escribió la obra. Ejemplo de ello son los términos en español y en itálica en el original para los que da una explicación en francés, entre paréntesis. Así ocurre con las siguientes expresiones: estancia, alero, chacra, poncho, lazo, caña, reñidero, querencia, carbonada, puchero, pastel, rastreador, puesteros, yerba, brasero, ombú, etcétera. Se evidencia en la autora una fuerte intención informativa y didáctica. Sin embargo, hemos creído necesario proponer algunas correcciones sobre costumbres y nombres de animales, ya que, como en otros autores europeos, se identifica a animales argentinos con los de otros continentes: por ejemplo se confunde avestruz y ñandú, jaguar y yaguareté, denomina gacela al guazuncho, perro de las praderas a la vizcacha, ibis a la garza, águilas americanas a los caranchos.

La escritora suiza no conoce en profundidad la idiosincrasia de ciertas aves de la región. Ejemplo de ello es cuando habla de cotorras, colibríes y palomas de la virgen posándose sobre el lomo de alguna vaca, hecho que no ocurre en nuestra geografía.

También emplea términos desconocidos en nuestro vocabulario y en costumbres tales como kiapi y kilicón. Nuestras indagaciones no han podido dar cuenta de antecedentes de estas expresiones.

Hay en las tres novelas una mirada condescendiente de la autora para con las poblaciones de estas regiones: en el texto aparecen sutiles alusiones a la superioridad europea en lo que 
“Transfer” XV: 1-2 (2020), pp. 451-473. ISSN: 1886-554

hace al apego al trabajo, la creatividad y la industriosidad. Sirvan de ejemplo estas frases:

Hay que hacer notar que los pueblos pobres, nómades, contemplativos, perezosos, están todos más o menos preocupados con la idea de descubrir tesoros, forma cómoda de procurarse las riquezas que los pueblos activos e industriosos encuentran en las invenciones de su genio y en las fuerzas de sus brazos. (Crolla 2018: 68)

Las chacras cultivadas por los europeos se hacían notar por el orden y la simetría de sus cultivos, cosa que los gauchos desdeñan o ignoran. (Crolla 2018: 88)

El desdén de esta protestante por el clero católico no deja pasar ocasión para manifestarse, como en el caso del cura que lleva a su gallo al reñidero:

En el momento en que sir Henry se aproximaba vio descender del caballo a un personaje sin abrigo, con un chaleco verde de donde salían mangas de percal rosado; un pequeño cuello de satén negro bordado de perlas azules rodeaba su garganta. Con una mano sostenía la rienda y con la otra su gallo de riña. Era el cura del lugar, gran aficionado a esa clase de espectáculo, como la mayoría de sus cofrades. (Crolla 2018: 90)

En Fray Antonio, la mirada que Lina provee sobre este castigado misionero, contribuye sin embargo a la reflexión sobre las diferencias entre un mundo en decadencia y de fuertes contrastes sociales y las oportunidades que brinda el nuevo mundo, todavía virginal y potenciador, aún a pesar de la barbarie, al tiempo que fundamenta las propias convicciones religiosas del narrador omnisciente.

Y, sin embargo, el Hermano Antonio había sido privilegiado. Más feliz que aquellos oprimidos por la atmósfera viciada de nuestra vieja sociedad, le había sido dado respirar el aire libre y puro de un mundo nuevo. Esta alma aún palpitante por las angustias de la duda y llevando en ella la fe, como un tesoro que 
“Transfer” XV: 1-2 (2020), pp. 451-473. ISSN: 1886-554

se posee sin saber gastarlo, se había recogido en los sentimientos a los que se aferraba con más fuerza: Dios y la naturaleza.

No obstante, la vida no está completa sino para el hombre para quien ella no es un enigma sino la realización de un plan divino aceptado sin reservas y donde el sacrificio del momento presente se torna en esperanza del futuro. (Crolla 2018: 216)

Idea que Lina comparte con su esposo, Charles Beck quien escribe La République Argentine -inmenso manual descriptivo de estas geografías y costumbres destinado a los futuros inmi-grantes- y trabajará denodadamente durante sus veinte años como Cónsul argentino en Suiza, para promover la emigración de los desheredados de su tierra.

Pero lo que más nos asombra en los escritos de Lina, es su capacidad para dar testimonios de una época sobre personajes y costumbres de nuestra región en vivencias coloridas que en muchos casos aún perduran, y el innegable ideal humanitario que la caracteriza, y que permea en toda su obra.

\section{Philippe Greffet}

Greffet llegó a la ciudad de Santa Fe como director de la Alianza Francesa que acababa de crearse en 1949 en esta ciudad. El joven maestro, poseedor de sus diplomas universitarios y muy versado en literatura originario de Lyon, dejaba atrás la pesadilla de los años de guerra y se sumergía en este que sería para él su nuevo mundo. En su artículo "L'Alliance Française d'Amérique latine a quatre fois 25 ans" (Greffet 1988: 99) evoca el deslumbramiento que le provoca su desembarco en Buenos Aires, las luces de la calle Corrientes, su primer "Bife" de la deliciosa carne argentina. Más tarde, en Santa Fe, descubrirá en este nuevo mundo los verdaderos valores, "otra riqueza menos efímera que la del peso: la amistad” (Greffet 1988: 100; la traducción es nuestra). Aquí hará 
“Transfer” XV: 1-2 (2020), pp. 451-473. ISSN: 1886-554

amistades que perdurarán en el tiempo y en la distancia, a lo largo de su ascendente carrera como director de la Alianza Francesa de Santa Fe; Adjunto del inspector general de las Alianzas Francesas de Argentina; Delegado general de las Alianzas Francesas de Brasil; Consejero cultural y de cooperación científica y técnica en Uruguay y luego en Argentina; Consejero técnico del Alto comité de la lengua francesa en el gabinete del Primer Ministro Francés y finalmente, Secretario general de la Alianza Francesa de París de 1978 hasta 1988. También será profesor ad honorem en la Universidad de Buenos Aires.

En Santa Fe y desde su cargo de director de la Alianza, será un gestor activo del movimiento cultural de la ciudad, interactuando con pintores, músicos, escritores, cineastas, periodistas, docentes, editores. En sus palabras, este período fue "el embelesamiento, el renacimiento, la integración en un mundo puro y entusiasta, enamorado de mi país" (Greffet 1988: 100; la traducción es nuestra).

Además de las múltiples actividades culturales desarrolladas en la Alianza, entre ellas la creación de un grupo de teatro con sus estudiantes y docentes, Greffet será -y por mucho tiempo- un asiduo colaborador del diario local El Litoral. Más de doscientas notas -muy esperadas por los lectores- fueron publica-das no sólo en su período de estadía en Santa Fe sino también durante el resto de su carrera, desde Buenos Aires, Uruguay, Río de Janeiro, París o Lyon. En el ejemplar que posee la biblioteca de la Alianza de un centenar de notas -entre las más de doscientasredactadas entre 1992 y 2004, escogidas y reagrupadas por el mismo Greffet en un mimeo Miscelánea Periodística, aborda temas tan variados como la pintura y el arte, los deportes, la política, Francia de hoy y de siempre, la cultura.

Pero Greffet también será un poeta que canta a Santa Fe: a sus calles, a sus gentes, al Río Paraná, al Puente Colgante, a los pescadores... con sus fábulas para todos, capaces de maravillar como lo demuestran sus dos volúmenes (en edición bilingüe) Le 
“Transfer” XV: 1-2 (2020), pp. 451-473. ISSN: 1886-554

petit bateau de papier. En el prefacio del segundo de ellos nos dice Greffet:

En 1949 el Quai d' Orsay me confió la dirección de la Alianza Francesa de Santa Fe. Acompañado por Roger Gouze que fue mi primer maestro en cuestiones americanas, descubrí una peque-ña ciudad simpática, algo adormecida, cuyo símbolo era un magnifico puente colgante que era para Santa Fe, lo que la Torre Eiffel es para París o el Golden Bridge es para San Francisco. Ese puente que permitía un acceso hacia el sur de la región (sic) captó mi atención desde la primera mirada, ya que había sido fabricado en Francia en los talleres de la Gironde. Éramos enton-ces, el puente y yo, compatriotas y además, los dos nacidos en 1924. De allí una cierta complicidad que me llevó a escribir un poema titulado en español "El puente colgante". (...) En 1983 una creciente terrible que no podemos imaginar en nuestros climas, infló el Paraná y su afluente el Salado. Este verdadero mar de furia arrasó todo a su paso y el puente colgante no pudo resistir a la corriente que lo llevó al fondo del lecho. Allí iba a permanecer por cerca de 20 años. (Greffet 2006: 11; la traducción es nuestra).

El puente colgante será uno de los temas de la serie de seis poemas en versión bilingüe de su libro Le petit bateau de papier. En un estilo que evoca mucho a la frescura de Prévert, Greffet hace una remembranza de sus años pasados en Santa Fe. Fue para él, sin duda, un período muy feliz de su vida, tanto más cuanto que aquí encontró a la mujer con la que se casó y tuvo sus hijos, Nicole Courault, ella misma y su familia relacionados con la Alianza Francesa. Los avatares del puente, su origen, con el que se asimila por la fecha de nacimiento y por el país de proveniencia, la destrucción y el desmantelamiento y finalmente su reconstrucción componen la trama de estos tres poemas que él mismo tradujo en la edición que nos ocupa.

Es interesante ver el origen de su producción bilingüe. En el "Préambule" del primer volumen de El barquito de papel, Greffet nos cuenta que, siendo él Consejero cultural de la Embajada de Francia en Uruguay, en 1967, el ministro de educación de ese país, 
“Transfer” XV: 1-2 (2020), pp. 451-473. ISSN: 1886-554

licenciado en la Sorbona, le pidió a través de la Directora de la enseñanza primaria traducir cierto número de grandes autores franceses que habían escrito para niños. Esto dice Greffet con respecto a la traducción:

Aussitôt rentré à l'Ambassade je me mis à l'ouvrage et bien vite je m'aperçus de l'impossibilité de traduire en français des textes écrits pour les enfants dans un autre langue. Il y a en effet tout un contexte que traduisent les onomatopées et des images sui generis. Plus que jamais l'adage se vérifiait: "Traduire c'est trahir". Que faire pour dépanner nos amis? (Greffet 2006: 9)

Greffet, que había recibido en 1959 el Gran premio de literatura de Río de Janeiro -compitiendo con Blaise Cendrars y ganándole- por su libro de poemas Río de tous les coeurs, y que luego había publicado una serie de poemas en español, se decidió a escribir un número de poemas inspirado por el bestiario sudamericano. Sigue Greffet:

Dans leur grande majorité ce sont ces textes que présente ce livre mais au préalable il me fallait convaincre mes amis français de la qualité de ces pièces, d'où le retour du même problème: l'auteur est-il trahi par le traducteur? Ici, le traducteur étant à la fois l'auteur, le risque de provoquer un conflit n'existait pas. (Greffet 2006: 11)

Aclara luego que el español del que se trata es el argentino y señala a continuación diferencias entre uno y otro de tres tipos: semánticas, morfológicas y prosódicas, dando ejemplos de cada una. Concluye diciendo que el ministro se mostró satisfecho de su trabajo que fue grabado en forma de CD titulado Gaviotas en el aire (Mouettes dans le vent).

Transcribimos a continuación los tres poemas sobre el puente tal como aparecen en sus versiones en francés y en español: 
“Transfer” XV: 1-2 (2020), pp. 451-473. ISSN: 1886-554

\begin{tabular}{|l|l|}
\hline \multicolumn{1}{|c|}{ Le pont suspendu } & \multicolumn{1}{c|}{ El puente colgante } \\
Pont & Puente \\
Petit pont de mes soupirs & Puentecito de mis suspiros \\
Je suis né comme toi & He nacido como tú \\
En belle et douce France & En la bella y dulce Francia \\
& \\
Pont & Puente \\
Petit pont de mes amours & Puentecito de mis amores \\
Je suis né comme toi & He nacido como tu \\
En el veinticuatro & En el veinticuatro \\
& \\
Pont & Puente \\
Petit pont de mes oublis & Puentecito de mis olvidos \\
Je suis né comme toi & He nacido como tú \\
Dur comme fierro & Duro como fierro \\
& \\
Pont & Puente \\
Petit pont d mes désirs & Puentecito de mis deseos \\
Je suis né comme toi & He nacido como tú \\
Endurant le poids & Aguantando el peso \\
Le poids des autres & El Peso de los demás \\
Des autres qui passent & Los demás que pasan \\
Ignorant les soupirs & Ignorando los suspiros \\
Des amours qui sont nées & Y los amores que nacieron \\
Sur ton épaule & En tu hombro \\
Petit pont & Puentecito \\
Ton épaule forte & Tu hombro fuerte \\
Plus forte avec le temps & Y más fuerte con el tiempo \\
Plus riche avec les ans & Y más rico con los años \\
Comme un vieux saint & Tal como un santo viejo \\
Julien ou Emilion & Julián o Emilión \\
Comme un vin vieux & Tal como un vino viejo \\
De Bordeaux & De Burdeos \\
& \\
Pont & Puente \\
Petit pont de mes souvenirs & Puentecito de mis recuerdos \\
Je suis né comme toi & He nacido como tú \\
Pour traverser & Para cruzar \\
\hline
\end{tabular}


“Transfer” XV: 1-2 (2020), pp. 451-473. ISSN: 1886-554

\begin{tabular}{|l|l|}
\hline Les fleuves. & Los ríos \\
\hline
\end{tabular}

\begin{tabular}{|l|l|}
\hline \multicolumn{1}{|c|}{ Le pont pendu } & \multicolumn{1}{c|}{ Puente Colgado } \\
Qu'ont-ils fait de toi? & ¿Qué hicieron de ti? \\
Pont & Puente \\
Petit pont & Puentecito \\
De mes vertes années & De nuestros años verdes \\
& \\
Qu'ont-ils fait de toi ? & ¿Qué hicieron de ti? \\
L'eau & El agua \\
Couleur de lion & Color de león \\
Et l'homme & Y el hombre \\
L'homme couleur de brigand & El hombre color de ladrón \\
& \\
Qu'ont-ils fait de toi ? & ¿Qué hicieron de ti? \\
Pont & Puente \\
Petit pont & Puentecito \\
De mes amours ? & De mis amores \\
& \\
Qu'ont-ils fait de toi ? & ¿Qué hicieron de ti \\
Qu'ont-ils fait de moi $?$ & ¿Qué hicieron de mí? \\
Le temps & El tiempo \\
Le temps & El tiempo \\
Couleur de la mort & Color de la muerte \\
Et le vent & Y el viento \\
Le vent & El viento \\
Couleur de l'oubli & Color del olvido \\
& \\
Car encore & Todavía, \\
O mémoire & O memoria \\
Chante le vent & Canta el viento \\
Dans ta lyre & En tu lira, \\
C'était le temps & Era el tiempo \\
Sans temps & Sin tiempo \\
\hline
\end{tabular}


“Transfer” XV: 1-2 (2020), pp. 451-473. ISSN: 1886-554

\begin{tabular}{|l|l|}
\hline De ma folle jeunesse & De mis años mozos \\
«Setubal » & «Setúbal» \\
Criait le vent & Gritaba el viento \\
C'est ton bal & Es tu baile \\
Sifflait l'écho & Chillaba el eco \\
Et l'on riait, l'on riait & Y nos reíamos, nos reíamos \\
«Setubal » & « Setúbal » \\
Hurlait le vent & Gritaba el viento, \\
«C'est tombal » & «Es tumbal» \\
Pleure l'écho & Llora el eco \\
Fini de rire & Ya no reímos \\
& \\
Qu'ont-ils fait de toi ? & ¿Qué hicieron de ti? \\
Pont suspendu & Puente colgante \\
Pont pendu & Puente colgado \\
Et mutilé & Y mutilado \\
Pont amputé & Puente amputado \\
Ecartelé & Descuartizado \\
Et démembré & Y desmembrado \\
Sur le pont & \\
D'Avignon & En el puente \\
On y danse & De Aviñón \\
On y danse & Cómo bailan \\
Sur le pont & Cómo danzan \\
Petit pont & \\
De mes années & En el puente \\
Plus calmes & Puentecito \\
On ne danse pas & De mis años \\
Et même & Viejos \\
On ne traverse plus & No se baila \\
Le fleuve. & No se danza más \\
& Y ya \\
& No se cruza más \\
& El río. \\
& \\
\hline & \\
& \\
&
\end{tabular}


“Transfer” XV: 1-2 (2020), pp. 451-473. ISSN: 1886-554

\begin{tabular}{|l|l|}
\hline \multicolumn{1}{|c|}{ Le pont ressuscité } & \multicolumn{1}{|c|}{ El puente resucitado } \\
Qu'ils viennent & \\
Qu'ils reviennent & ¡Que vengan! \\
Les soupirs & iQue vuelvan \\
Et les amours & ¡Los suspiros \\
O bien-aimée & Y los amores! \\
Que resplandisse & Oben amada \\
La joie & ¡Que resplandezca \\
De tes noces & La alegría \\
Avec le fleuve & De tus bodas \\
Qui rugit & ¡Con el río \\
Ou ronronne & Que ruge \\
& O ronronea! \\
Pont & \\
Petit pont & Puente \\
De mes vertes années & Puentecito \\
Pont & De mis años verdes \\
Petit pont de mes vertes & Puente \\
amours & Puentecito de mis amores \\
Pont & Puente \\
Pont de câlin & Puentecito cariñoso \\
Puisse à jamais & Pueda para siempre \\
Résonner & Resonar \\
Dans ta lyre verte & En tu lira verde \\
Le cantejondo vert & El cante jondo verde \\
Des amours ressuscitées & De los amores resucitados \\
(...) & (...) \\
Pont & Puente \\
Petit pont & Puentecito \\
De l'avenir & Del porvenir \\
Salut! & ¡Salud! \\
\hline
\end{tabular}

Algunos efectos de la autotraducción se han notado en este poema. Por ejemplo "O bien aimée" da "Oben amada". Greffet, deja ver las interferencias del portugués (su tercera lengua fue adquirida durante su estadía en Brasil y aparece episódicamente 
“Transfer” XV: 1-2 (2020), pp. 451-473. ISSN: 1886-554

en sus poemas). En otras piezas del conjunto, por ejemplo en el poema "Si j'étais riche", decide dejar, en la tirada en francés, la expresión en portugués: "Un tango de Gardel/pour notre saudade". (Greffet, 2006:23). En el poema "Spleen": "nous fîmes le tour de la ville/ en lotaçao", y en su versión al español titulada igualmente "Spleen", Greffet opta por: "Dimos la vuelta a la ciudad/en lotaçao" (Greffet, 2006:86). En el poema "Le jardín zoologique de Río”, “J’ai vu le Piranha” lo traduce como "He visto el piraña", con género masculino. Otro riesgo de la autotraducción es el descono-cimiento del uso de los términos. Así, por ejemplo, en el poema "Le requin", que tiene cinco repeticiones del verbo "bouffer": "Le requin a bouffé / le merou/ Le mérou qui avait bouffé le brochet / Le brochet qui avait bouffé le goujon / Le goujon qui avait bouffé la mouche (...) Le fromage que Jules a bouffé à son tour". En la traducción leemos: "El tiburón jamó el mero / El mero que jamó el lucio / El lucio que jamó el gobio / El gobio que jamó la mosca (...) / El queso que Julio jamó a su vez (Greffet 2006: 67). La expresión "jamó" es de uso desconocido en el español rioplatense, aunque la voz "jamar" sí aparece en el diccionario de la RAE que da su proveniencia del Caló: es decir, "comer", en registro coloquial o argótico. En español rioplatense la traducción debería haber sido "morfó".

Estas simples observaciones no empañan en absoluto la frescura y la originalidad de todo el conjunto que expande su musicalidad y sobre todo, una cierta nostalgia, plasmando en él todo el cariño y la riqueza que su experiencia santafesina significó en su vida.

Los tres autores han contribuido sin lugar a dudas a enriquecer el acervo cultural de nuestra ciudad y merecen ser reconocidos. Marta Samatan lo es en una biblioteca y espacio universitario que lleva su nombre, Lina Beck Bernard es evocada por los trabajos de investigación del Centro de Estudios Comparados dirigido por la profesora A. Crolla. Philippe Greffet aguarda su momento aunque periodistas del diario El Litoral e 
“Transfer” XV: 1-2 (2020), pp. 451-473. ISSN: 1886-554

intelectuales de la ciudad vinculados con la Alianza Francesa de Santa Fe lo tienen muy presente en su memoria.

\section{Referencias bibliográficas}

CROLLA, Adriana. (2019). "Reseña del libro de Lina Beck Bernard, Trilogía narrativa y ensayos." TRANSFER, Vol. 14, pp. $1 / 4$. En: $\quad<<$ http://dx.doi.org/10.1344/transfer.2019.14.231$234>>$ (Última fecha de consulta 25/05/2019).

---. (Ed.). (2018). Trilogia Narrativa y ensayos, Lina Beck-Bernard. ISBN 978-987-749- 100-5. Santa Fe: Ediciones UNL.

CROLLA, Adriana \& ZENARRUZA, Silvia. (2017). La traducción como tradición. Traduciendo la Pampa Gringa. TRANSFER, Vol. 12, pp.1/25. (Última fecha de consulta 25/05/2019) En: << http://dx.doi.org/10.1344/transfer.2017.12.72-96>>

COUDANES, Mariela. (2011). Tradición y Cambio social en dos regiones de América del Sur. Mujeres elquinas y santafesinas en la narrativa de Marta Samatan, Issn 0718-9427 (Última fecha de consulta 25/05/2019)

En:<<file:///C:/Users/Usuario/Documents/DialnetTradicionYCambioSocialEnDosRegionesDeAmericaDelSur3820371.pdf $>>$

GREFFET, Philippe. (1988). Caravelle. Cahiers du monde hispanique et luso-brésilien, Année 1988, 50: 99-106. En : $<<$ https://www.persee.fr/doc/carav_11476753_1988_num_50_1_2361>>

GREFFET, Philippe \& DUCROQUET, Jean. (2005). Le petit bateau de papier - édition bilingue français-espagnol, album pour enfants - Tome I, Éditions des mots d'elle. ISBN: 2-915824.0209

----. (2006). Le petit bateau de papier - édition bilingue françaisespagnol, album pour enfants - Tome II. Éditions des mots d'elle. ISBN: 2915824029 
“Transfer” XV: 1-2 (2020), pp. 451-473. ISSN: 1886-554

MENIN, Ovide. (2001). Marta Samatan Edición homenaje en el centenario de su nacimiento 1901 - 2001. Opúsculo editado por AMSAFE LA CAPITAL. Santa Fe.

TRAVADELO, Delia. (2001). Marta Samatan, maestra. Santa Fe: Centro de publicaciones UNL.

Fecha de recepción: 2.05.2019 Fecha de aceptación: 01.06.2019

\section{Resumen:}

Tres personalidades que han transitado por nuestra ciudad han dejado una huella en las letras y en la cultura de nuestra querida Santa Fe: Lina Beck Bernard, esposa del fundador de la colonia de San Carlos y testigo de una época poco documentada, nos presenta en sus relatos La estancia Santa Rosa y Telma vivencias de mediados del siglo XIX.

Marta Samatan, maestra, escritora y fundadora de una asociación de mujeres pionera en Argentina ilustra las letras santafesinas y es la primera traductora oficial de la Universidad Nacional del Litoral.

Philippe Greffet, primer director de la Alianza francesa en Santa Fe, deja en sus relatos y en sus múltiples artículos para el diario local su impronta poética de extranjero enamorado de estas tierras.

Los tres han enriquecido el acervo literario local y merecen ser evocados.

Palabras clave: Actores culturales, Traducción, Cultura francesa. 
“Transfer” XV: 1-2 (2020), pp. 451-473. ISSN: 1886-554

\title{
GENDER AND TRANSLATION. THREE PERSONALITIES IN THE CULTURE OF SANTA FE: MARTA SAMATÁN, LINA BECK BERNARD, PHILIPPE GREFFET
}

\begin{abstract}
:
Three personalities have left an indelible memory in the culture of our city of Santa Fe: Lina Beck Bernard, wife of the founder of San Carlos colony and eyewitness of an undocumented time, shows us in her writings La estancia Santa Rosa and Telma, life experiences from around the middle of the XIXth century.

Marta Samatán, teacher, writer and founder of a woman's association pioneer in Argentina, illustrates the letters of Santa Fe and she is the first official translator of the Universidad Nacional del Litoral.

Philippe Greffet, first director of the "Alliance Française de Santa Fe", shows in his stories and in his many articles for the town's newspaper El Litoral his poetical vision of a foreigner in love with this region.

The three of them have enriched the local cultural heritage and deserve to be evoked.
\end{abstract}

Keywords: Cultural Actors, Translation, French Culture. 